Illustrating the truth of the above item taken from a recent medical journal, I wish to report a case which came under my observation recently:

C. M. was sent to me by Dr. K. to be fitted with glasses. He had been complaining of failing vision for about four weeks in right eye and for two weeks in left eye. Vision was equal to counting fingers at ten feet. No improvement with glasses. Ophthalmoscopic examination showed extensive patches of albuminuric retinitis in both eyes. I then questioned him about his general health, which he said was very good. Had not been sick and felt as well as usual. No trouble with kidneys as far as he knew. I sent him back to his family physician, Dr. K., with a letter, telling him what I had found, and asking him to make a careful examination of the patient's urine for albumen, and to put him on treatment. In a few days I received a letter from the Doctor stating that he had found C. M.'s urine very heavily loaded with albumen. Fifteen days after the first examination I again saw the patient, and he was still feeling about the same. Vision in right eye was equal to counting fingers at five feet, and in left eye to counting fingers at ten feet. At this time I am satisfied he would have been accepted as a good risk by any life insurance company that did not require an examination of the urine, and many good companies do not. He took his bed shortly after this, developin in a short time all the well marked symptoms of Bright's disease, and died in five weeks from the last examination.

Oren Oneal, M.D.

\section{Archiv fur Verdauungs Krankheiten.}

Baltimore, M d., Feb. 12, 1895.

To the Editor:-The rise of a specialty in medicine is marked by the appearance of journals especially devoted to it. We are glad to inform you, that the new specialty of "Diseases of the Digestive Organs" is about to have its own publication-the Archiv für Verdauungs krankheiten which will appear in April. It will be published in Berlin, Germany, by S. Karger. The editor is Dr. I. Boas, the wellknown author of a work on "Diseases of the Stomach." $\mathrm{He}$ will be assisted by specialists in Germany and other countries. The Archiv will contain original articles, besides reviews and abstracts of recent literature, and will embrace diseases of the stomach, intestine, liver, pancreas and peritoneum, constitutional diseases and dietetics. Those interested may communicate with the editor or the publisher.

Yours, etc.,

Julius Friedenwatd, M.D.

To Military and Naval Medical Officers.

To the Editor:-The undersigned, members of the "Committee on Litter," appointed by the Association of Military Surgeons of the United States, to report at the approaching annual session a desirable form of military litter for the comfortable, safe and expeditious transportation of the sick and wounded,solicit from medical officers of the National Services and the National Guard of the several States, suggestions, plans or models of such an appliance, to be delivered to either of them at their respective addresses, on or before the first of April, 1895.

Aibert L. Gihon, Medical Director, U. S. Navy, U. S. Naval Hospital, Washington, D. C. JoHN VAN R. HoFf, Major and Surgeon, U. S. Army. Governor's Island, Harbor of New York

Myles Standish, Capt. and Asst. Surgeon, M. V. M., 200 Dartmouth Street, Boston, Mass.

The Surgical Section.

Hartford, Conn., Feb. 9, 1895.

To the Editor:-Will you kindly give me the name and address of the Secretary of the Surgical Section of the AMERICan Medical Association? Yours truly,

M. M. Johnson, M.D.

ANswer:-Joseph Ransohoff, M.D., 296 Walnut Street, Cincinnati, is Chairman, and Reginald H. Sayre, M.D., 285 Fifth Avenue, New York City, is Secretary. We have printed these names each week since the San Francisco meeting.

\section{BOOK NOTICES.}

A Manual of Diagnostic Neurology for General Practitioners and Students. By AleXander B. Shaw, M.D. Illustrated. St. Louis, Mo. 1894.

This little work of 114 pages makes a decidedly favorable impression. It is compact, and at the same time we note that there are no serious omissions in the description of the diagnostic relations of the nervous system. The arrangement of the book is excellent and accentuates the diagnosis of nervous diseases in a manner which will bring them home to the student and fix them in mind in a much better way than they can be obtained from the general treatises on nervous diseases. The first chapter deals with objective symptoms, such as aspect and expression, motor symptoms, ataxia, titubation, rotatory and choreic movements, tremor, and spasm in all its varieties. The reflexes are briefly considered, and we note that the writer does not regard the absence of them as always an evidence of a pathologic condition. In this we would heartily agree with him. It is the loss and not the absence of the reflexes which determine the value of this sign in the pathology of nervous diseases.

The diagram on page 10, showing the reflex centers of the spinal cord, will materially facilitate the regional dingnosis of cord lesions. Page 25 has an excellent diagram illustrating the varied effects of lesions of the motor and sensory paths from the cortex to the periphery. These ought to prove of great value to the beginner in nervous pathology. It is a simplification of the more complicated diagrams which are found in German works and is much easier of comprehension than most of the diagrams of this kind. On page 26 a case of myotonic spasm is reported, which is an exceedingly interesting one, and illustrates well the diagnostic relations of this condition. We doubt, however, the propriety of putting into a work of this kind a purely controversial matter such as that concerning this case.

Throughout the work the author has given us some excellent tables of the differential diagnosis of certain lesions of the nervous system. We would especially call attention to the table relating to the differential diagnosis of paralysis from cortical cerebral lesions and paralysis from non-cortical cerebral lesions. This, and the table showing the points of resemblance and difference between spinal apoplexy, hemato-myelitis, hemorrhage into spinal membranes, Landry's paralysis, acute poliomyelitis, painful paraplegia and acute central myelitis and multiple neuritis, are of especial value. Another table giving the differential diagnosis of monoplegia of central, spinal and peripheral origin, is one that will prove useful.

The writer says that tactile sensibility may be roughly estimated by touching the part to be examined by the finger or camel's hair pencil, and he gives the preference in testing sensation to the esthesiometer. In our judgment this instrument is of comparatively little value in neurologic work. Better resuits can be achieved by the use of a small pledget of cotton in determining tactile sensibility and its acuteness, and then by such simple means as varying weights, coins or other well-known objects placed in contact with the skin. These, combined with the use of a pin, will achieve much more accurate results and in less time than they can be reached with the use of the esthesiometer.

The chapters which relate to the diagnostic relations of the optic nerves and the testing of vision, as well as that which deal with aphasia, are exceedingly compact, well written, and contain about all that is of practical importance in the diagnosis of nervous diseases.

On the whole the work is well written; the illustrations are well selected, but many of them are very poorly printed. 